\title{
Assessment of correction formula for echocardiographic estimations of left ventricular volumes ${ }^{1}$
}

\author{
M. A. MARTIN \\ From the Departments of Cardiology and Therapeutics, The Royal Infirmary, Sheffield
}

SUMMARY A number of assumptions are inherent in the echocardiographic estimation of left ventricular volumes. Initial validation of the method compared echocardiographic and angiographic volume measurements. Reasonable correlation was shown between groups in these studies but with major differences in some individuals. Both methods assume an ellipsoid shape for the left ventricle but a standard echocardiographic volume formula (volume $=\mathrm{D}^{3}$ ) also assumes a fixed 2:1 ratio between the major and minor axes of the left ventricle. This ratio is only valid in normal sized hearts, and at extremes of heart size it can vary from 3:2:1 to $1 \cdot 2: 1$. This introduces a potential source of error into the echo method, but it has been suggested that a correction formula can compensate for the variable ratio at different cardiac sizes.

The validity of this formula has been assessed by using it to recalculate the results in four studies comparing echocardiographic and angiographic volumes. The recalculated correlation coefficients and their associated errors were compared with the original results and no consistent improvement was evident. In addition it has previously been shown that the correction formula is unhelpful in the presence of dyskinesia and it is, therefore, suggested that the general use of this formula in correcting echo volume estimations is not helpful.

Echocardiography has been used increasingly in recent years as a noninvasive method of estimating left ventricular volumes, and other derived indices of left ventricular function. An internal diameter of the left ventricle is measured from septal to posterior wall endocardium at both end-systole and end-diastole in a standardised way (Popp and Harrison, 1970). This measurement is used as a basis for estimating left ventricular volumes.

Since the echocardiographic derivation of left ventricular volume requires a number of assumptions to be made, the method was initially validated by comparing it with standard volume estimations from angiography (Fortuin et al., 1971; Pombo et al., 1971 ; Feigenbaum et al., 1972; Murray et al., 1972). These studies showed reasonable correlations between groups of patients using both methods, but with occasional large individual variation in results. Regression equations were derived to allow echo volumes to be estimated from the measurement of left ventricular internal diameter based on the angiographic data. These equations varied and in

1This work was supported in part by May \& Baker Limited Received for publication 25 April 1977 spite of these studies the accuracy and validity of echo volumes has been questioned (Linhart et al., 1975).

There are a number of reasons why these studies might have differed, and why there was sometimes pronounced variation in individual measurements between the two methods.

Differences between the two methods may occur especially at the extremes of heart size. A major potential source of error results from the assumptions echocardiography makes about the geometry of the left ventricle and its relation to the internal diameter as measured by echo. One of the earliest formulae for echo ventricular volume, $V=D^{3}$, where $\mathrm{D}=$ echo internal diameter in $\mathrm{cm}$ is derived from the formula for the volume of an ellipsoid of revolution assuming that the major axis of the ellipsoid has a fixed two-to-one relation to the minor axes. all of which are equal (Pombo et al., 1971). Though this appears to be a reasonable approximation in normal sized hearts, it is definitely not true at the extremes of cardiac size (Popp et al., 1973).

Variability in the ratio between major and minor axes would introduce errors into the echo estimations using this formula. 
Recently it has been suggested that a correction can be made to this formula which makes allowance for this variability, thus raising hopes of improving the accuracy of the echo method (Teichholz et al., 1974, 1976).

\section{Methods}

Teichholz and his co-workers showed in a retrospective analysis of 100 ventriculograms that the major to minor axis ratio varied from $3 \cdot 2: 1$ to $1 \cdot 2: 1$. They showed a relation between the minor axis, which was assumed to be equivalent to the echo internal diameter, and the major to minor axis ratio. This relation was used to derive a correction formula which should compensate for the variability of this ratio.

$$
V=\left(\frac{7 \cdot 0}{2 \cdot 4+D}\right) \times\left(D^{3}\right), \text { where } D=\text { echo internal }
$$

diameter in $\mathrm{cm}$.

I have used this formula to recalculate the left ventricular and stroke volumes of the patients in the original comparative studies of echo with angiography (Fortuin et al., 1971; Pombo et al., 1971; Feigenbaum et al., 1972; Murray et al., 1972). From these data correlation coefficients and their associated errors were calculated comparing corrected echo volumes with the original angiographic data, and these results were compared with the original studies to assess the effect of the correction formula.

\section{Results}

The use of the correction formula produced only modest changes in correlation coefficients and the associated errors from the original studies (Table). There was deterioration as well as improvement in the corrected correlations, but overall no consistent improvement.

\section{Discussion}

The cavity of the left ventricle is at present considered to be an ellipsoid of revolution and there is evidence that this is a reasonable approximation, at least in normal hearts, and in the absence of dyskinesia (Dodge et al., 1966; Greene et al., 1967; Sandler and Dodge, 1968).

Angiographic volume estimation uses measurement of both major and minor axes and will, therefore, correct at least in part for variability in the ratio between axes.

Echocardiographic internal diameter approximates to the angiographic minor axis (Fortuin
Table Assessment of use of correction formula $\mathrm{V}=\left(\frac{7}{2 \cdot 4+\mathrm{D}}\right) \times\left(\mathrm{D}^{3}\right)$ applied to studies of ventricular volumes

\begin{tabular}{|c|c|c|}
\hline \multirow{2}{*}{$\frac{\text { Source }}{\text { End-diastolic volume }}$} & \multicolumn{2}{|c|}{ Echo versus angiography } \\
\hline & $\begin{array}{l}\text { Correlation } \\
\text { coefficient }\end{array}$ & $\begin{array}{l}\text { Standard error of } \\
\text { estimate }(\mathrm{ml})\end{array}$ \\
\hline Murray-original & 0.81 & $47 \cdot 0$ \\
\hline Murray-corrected & 0.81 & $47 \cdot 8$ \\
\hline Fortuin一original & 0.83 & $47 \cdot 0$ \\
\hline Fortuin-corrected & 0.83 & $47 \cdot 0$ \\
\hline Feigenbaum-original & 0.89 & $55 \cdot 0$ \\
\hline Feigenbaum-corrected & 0.89 & $57 \cdot 1$ \\
\hline Pombo-original & 0.97 & $27 \cdot 7$ \\
\hline Pombo-corrected & 0.96 & $30 \cdot 1$ \\
\hline \multicolumn{3}{|l|}{ End-systolic volume } \\
\hline Murray-original & 0.66 & $33 \cdot 0$ \\
\hline Murray-corrected & 0.66 & $32 \cdot 7$ \\
\hline Fortuin—original & 0.80 & $42 \cdot 0$ \\
\hline Fortuin-corrected & 0.81 & $37 \cdot 0$ \\
\hline Feigenbaum-original & 0.81 & $43 \cdot 0$ \\
\hline Feigenbaum-corrected & 0.91 & $43 \cdot 6$ \\
\hline Pombo-original & 0.97 & $32 \cdot 6$ \\
\hline Pombo-corrected & 0.97 & $24 \cdot 6$ \\
\hline \multicolumn{3}{|l|}{ Stroke volume } \\
\hline Murray-original & 0.81 & $31 \cdot 0$ \\
\hline Murray-corrected & 0.85 & $27 \cdot 0$ \\
\hline Fortuin-original & 0.83 & $19 \cdot 4$ \\
\hline Fortuin-corrected & 0.74 & $23 \cdot 0$ \\
\hline Feigenbaum-original & 0.75 & $30 \cdot 5$ \\
\hline Feigenbaum-corrected & 0.75 & $35 \cdot 0$ \\
\hline Pombo-original & 0.83 & $29 \cdot 4$ \\
\hline Pombo-corrected & 0.65 & $39 \cdot 9$ \\
\hline
\end{tabular}

et al., 1971; Pombo et al., 1971). However, the cube formula presumes a fixed ratio of $2: 1$ between major and minor axes, and this is a potential source of error. A correction formula which avoids this error would be very useful. If such a formula were generally applicable one would expect it to improve the correlations and errors in the original comparative studies, especially as these included patients with a wide range of ventricular diameters. However, this does not seem to be the case with the formula under discussion in spite of the fact that its validity appears to have been accepted (Feigenbaum, 1976; Popp, 1976).

Another study (Sweet et al., 1975) showed no improvement using the formula in patients with dyskinesia and this was also true in the study used to validate the formula (Teichholz et al., 1976). It, therefore, appears that the general use of this formula is not helpful in correcting echo volume estimations.

\section{References}

Dodge, H. T., Sandler, H., Baxley, W. A., and Hawley, R. R. (1966). Usefulness and limitations of radiographic methods for determining left ventricular volume. American fournal of Cardiology, 18, 10-24.

Feigenbaum, H. (1976). Echocardiography, 2nd ed., p. 317. Lea and Febiger, Philadelphia. 
Feigenbaum, H., Popp, R. L., Wolfe, S. B., Troy, B. L., Pombo, J. F., Haine, C. L., and Dodge, H. T. (1972). Ultrasound measurements of the left ventricle. Archives of Internal Medicine, 129, 461-467.

Fortuin, N. J., Hood, W. P., Sherman, M. E., and Craige, E. (1971). Determination of left ventricular volumes by ultrasound. Circulation, 44, 575-584.

Greene, D. G., Carlisle, R., Grant, C., and Bunnell, I. L. (1967). Estimation of left ventricular volume by one plane cineangiography. Circulation, 35, 61-69.

Linhart, J. W., Mintz, G. S., Segal, B. L., Kawai, N., and Kotler, M. N. (1975). Left ventricular volume measurement by echocardiography: fact or fiction? American fournal of Cardiology, 36, 114-118.

Murray, J. A., Johnston, W., and Reid, J. M. (1972). Echocardiographic determination of left ventricular dimensions, volumes and performance. American fournal of Cardiology, 30, 252-257.

Pombo, J. F., Troy, B. L., and Russell, R. O. (1971). Left ventricular volumes and ejection fraction by echocardiography. Circulation, 43, 480-490.

Popp, R. L. (1976). Echocardiographic assessment of cardiac disease. Circulation, 54, 538-552.

Popp, R. L., Alderman, E. L., Brown, O. R., and Harrison, D. C. (1973). Sources of error in calculation of left ventricular volumes by echography (abstract). American fournal of Cardiology ,31, 152.
Popp, R. L., and Harrison, D. C. (1970). Ultrasonic cardiac echography for determining stroke volume and valvular regurgitation. Circulation, 41, 493-502.

Sandler, H., and Dodge, H. T. (1968). The use of single plane angiocardiograms for the calculation of left ventricular volume in man. American Heart fournal, 75, 325-334.

Sweet, R. L., Moraski, R. E., Russell, R. O., and Rackley, C. E. (1975). Relationship between echocardiography, cardiac output and abnormally contracting segments in patients with ischemic heart disease. Circulation, 52, 634-641.

Teichholz, L. E., Cohen, M. V., Sonnenblick, E. H., and Gorlin, R. (1974). Study of left ventricular geometry and function by B scan ultrasonography in patients with and without asynergy. New England Fournal of Medicine, 291, 1220-1226.

Teichholz, L. E., Kreulen, T., Herman, M. V., and Gorlin, R. (1976). Problems in echocardiographic volume determinations: echocardiographic-angiographic correlations in the presence or absence of asynergy. American fournal of Cardiology, 37, 7-11.

Requests for reprints to Dr M. A. Martin, Section of Therapeutics, The Royal Infirmary, Sheffield S6 3DA. 